\title{
Predictors of Change in Substance Abuse Status in Soldiers
}

\author{
Alireza Mehrazmay ${ }^{1}$; Alireza Karambakhsh ${ }^{1}$; Mahmood Salesi ${ }^{1}$; Mostafa Heydari ${ }^{1}$; \\ Khodabakhsh Ahmadi ${ }^{1, *}$ \\ ${ }^{1}$ Behavioral Sciences Research Center, Baqiyatallah University of Medical Sciences, Tehran, IR Iran \\ *Corresponding Author: Khodabakhsh Ahmadi, Behavioral Sciences Research Center, Baqiyatallah University of Medical Sciences, P. O. Box: 19945-581, Tehran, IR Iran. Tel: \\ +98-2182482475, E-mail: kh_ahmady@yahoo.com \\ Received: November 24, 2013; Revised: October 18, 2014; Accepted: March 1, 2015
}

\begin{abstract}
Background: Military service is a stressful task that influences the life style of army personnel. Several factors can make soldiers less capable of coping with stressful events; so they may try to start drug abuse or increase in the amount or diversity of substance abuse. Understanding factors responsible for this misbehavior among soldiers is crucial for their commanders to modify these factors.

Objectives: This study aimed to determine the predictors of change in substance abuse status in soldiers.

Patients and Methods:This cross-sectional research was conducted to evaluate the substance abuse status among Iranian soldiers in 2010. The target population was the soldiers who had spent at least 3 months of their military service. Cluster sampling was done from army service garrisons in 12 provinces in Iran. A total of 3960 soldiers were selected with different levels of education and age. Data gathering was done with demographic questionnaires, Texas Christian university (TCU) drug screen II and ASI questionnaire (fifth edition). Four types of dependent variables were defined: "improvement", "without change", "deterioration", and "severe deterioration". Backward ordinal regression analysis was done and Pvalues, OR, and SE were calculated by SPSS19 software.

Results: Totally, $6.7 \%$ of soldiers improved, $82 \%$ remained without change, $6.1 \%$ deteriorated, and $5.2 \%$ severely deteriorated with regard to their substance abuse. Modifiable predictors were distance from home lower than $200 \mathrm{~km}(\mathrm{OR}=1.54)$, bad relationship with commanders $(\mathrm{OR}=1.88)$, service place dissatisfaction $(\mathrm{OR}=1.39)$, and always feeling lonely $(\mathrm{OR}=1.83)$. Non-modifiable factors were alcohol use within family and friends $(\mathrm{P}=0.000)$; psychiatric drug use history $(\mathrm{OR}=1.72)$; suicidal attempt history $(\mathrm{OR}=1.31)$; divorce, separation, and extramarital contact $(\mathrm{P}=0.001)$; unemployment $(\mathrm{P}=0.019)$; leisure time dissatisfaction $(\mathrm{P}=0.004)$; living alone $(\mathrm{OR}=2.43)$; and substance abuse onset before age $15(\mathrm{OR}=1.71)$.

Conclusions: Considering non-modifiable risk factors, leaders and commanders may recognize more vulnerable soldiers and try to resolve modifiable factors and decrease the risk of getting worse (with respect to substance abuse) about 7.3 times.
\end{abstract}

Keywords: Military Personnel; Substance-Related Disorders; Risk Factors

\section{Background}

Iran is located in a high risk region of drug production and traffic called "the Golden Crescent". Its neighbor, Afghanistan, is the largest source country for opiates and cannabis worldwide and the other neighbor, Pakistan, has long been an important hub for heroin trafficking because of a number of geographic reasons (1). Official reports estimated 1.8 million drug users in Iran; 9\% to 16\% of them are injection drug users, either as their primary or ancillary mode of drug use (2). Smoking and alcohol use disorders prevalence in men are estimated as $21.7 \%$ and $0.50 \%$, respectively in men in Iran $(3,4)$.

About $45 \%$ of Iran population are under 24 years old (5) and one of the high risk places for them to get addicted is military environments (6). There is a 24-month mandatory military service for all males over 18 years old in Iran. Military service is a special and stressful task that influences the life style of soldiers. Being far away from family and friends, having higher responsibility and numerous missions, as well as hard training are among the stressful characteristics of this period. Results revealed that up to $67 \%$ of the military personnel suffer from a high level of stress (7), which leads to job dissatisfaction (8). Most major theories of addiction have postulated that acute and chronic stress play an important role in the motivation to abuse addictive substances and relapse vulnerability (9-16). So substance abuse is a military service problem due to soldiers' 'avoidance' coping strategy (17-19). Izadi et al. showed that $15.7 \%$ of Iranian soldiers were tobacco addicted and $75 \%$ of them started that before military service (20).

This problem is associated with negative mental and physical health consequences and drop in military tasks efficacy, including being late to workplace, early leaving the workplace without reason, experience of injury during work, lower level of performance, and work loss due to illness or injury related to substance use $(21,22)$. National security, military readiness, and operational stress can impact service members who had already developed problems with alcohol or drug use, particularly, when this problem continues in combat as a way of coping with the stress. Substance users, especially heavy users, were less likely to engage in health practices and more likely to get sick, visit physicians, and hospitalize.

Copyright (C) 2015, Iranian Red Crescent Medical Journal. This is an open-access article distributed under the terms of the Creative Commons Attribution-NonCommercial 4.0 International License (http://creativecommons.org/licenses/by-nc/4.0/) which permits copy and redistribute the material just in noncommercial usages, provided the original work is properly cited. 
Whereas military service personnel should be strong and healthy to work properly (22). Also, they often criticize military service obligation and more believe that it is a waste of time. Soldiers taking drugs get poor results in general and professional military trainings (23).

\section{Objectives}

Awareness of the effective factors on substance abuse status of soldiers in their military service is crucial for the prevention of deterioration in their situation. So the aim of this study was to determine the predictors of change in substance abuse status in soldiers.

\section{Patients and Methods}

\subsection{Study Design}

This cross-sectional research project was conducted to evaluate the substance abuse status among Iranian soldiers in 2010.

\subsection{Participants}

The target population was the Iranian soldiers in military service. Sampling method was combination of stratification and cluster sampling. First, the target population was stratified to Army, Air Force, and Navy. In each stratum, from 33 provinces of Iran, 12 provinces were selected as clusters and within each province, one garrison was selected. Selected provinces included West Azerbaijan, Ardebil, Alborz, Tehran, Chaharmahal and Bakhtiari, Khuzestan, Sistan and Baluchistan, Fars, Qom, Kurdistan, and Hormozgan. Then random sampling was done in each garrison. Inclusion criteria was servicing for at least for 3 months in 2010. Sample size was calculated considering study power as $80 \%$ ( $\beta=$ 0.2 ) which yielded the sample size of 3675 . To compensate for the probable missing information, the number was increased to 4000 cases. After data gathering, 40 questionnaires did not have enough information to be included in the analysis. Eventually, 3960 soldiers with the mean age of 21.8 years $(S D=2.4)$ were included in the study.

\subsection{Assessment Tool}

Self-reported questionnaires were administered to soldiers. Demographic questionnaire was used to assess the characteristics such as age, education level, marital status, job before military service, as well as kinds and methods of abused substances. Texas Christian University (TCU) Drug Screen II was used for all soldiers for primary screening of the substance abuse. Then, ASI questionnaire (fifth edition) was used to assess the medical, job prior to military service, substance and alcohol abuse, legal, family and mental status of soldiers. TCU Drug Screen II and ASI questionnaires validity and reliability have been confirmed in previous studies $(24,25)$.

\subsection{Measures}

\subsubsection{Dependent Variables}

The changes in substance abuse status after 3 months of the military service were self-reported (Did you change your smoking habits/alcohol use/drug abuse in military service?). The participants selected their responses from 4 choices of "I have increased," "I have decreased," "I have started in military service," and "I have not changed." These choices summed up and 4 "change types" were defined (Table 1). Use of any new substance was defined as "severe deterioration". Decreasing at least one substance abuse without increase in other substances was defined as 'improvement' and inverse situation was defined as "deterioration". Remaining without change in all three substances or combination of increase and decrease in them was defined as "without change".

\subsubsection{Independent Variables}

Predictive measures were chosen by an exploratory way to investigate associations with change in substance abuse status. Two groups of independent variables were considered: 1) non-modifiable factors that involved job prior to military service course, marital status, leisure time satisfaction, suicidal attempt history, psychiatric drug use history, alcohol use in family or with friend (although the alcohol use prevalence is not so common in Iran), living with family or alone, age of substance abuse onset; 2) modifiable factors that involved distance from home, bad relationship with commanders, service place dissatisfaction, always feeling lonely, combat situation, educational level.

\subsection{Analysis}

The obtained information was decoded and entered in SPSS version 19. Variables were included in multivariate modeling if $\mathrm{P}$ was less than 0.25 for each particular univariate association of the variables. Then a backward ordinal regression analysis was done and OR and SE of increase in the chance of progression in substance abuse status from "improvement" to "no change", then "deterioration", and finally "severe deterioration" were calculated for each variable. For multivariate analysis, the $\mathrm{P}$ value less than 0.05 was considered as significant.

\begin{tabular}{lcc}
\hline \multicolumn{3}{l}{ Table 1. Definitions of Dependent Variable Types } \\
\hline $\mathbf{1}$ & Change Types & Definition \\
$\mathbf{2}$ & Improvement & Decrease in at least 1 substance without increase in others \\
$\mathbf{3}$ & Without change & Remaining without change in all 3 substances or any combined change \\
$\mathbf{4}$ & Deterioration & Increase in at least 1 substance without decrease in others \\
\hline
\end{tabular}


Mehrazmay A et al.

\subsection{Ethical Consideration}

Ethical consideration approval code of this study was 89-360 (August 20, 2009). Participants' satisfaction and privacy were considered in all stages of the study.

\section{Results}

\subsection{Descriptive Statistics and Univariate Analysis}

The majority of participants were single (82.1\%), em- ployed (54.5\%) and with low level of education or illiterate $(71.1 \%)$. The frequencies of substance abuse status changes in them are presented in Table 2. Totally, 6.7\% of soldiers improved, $82 \%$ remained without change, $6.1 \%$ deteriorated, and $5.2 \%$ severely deteriorated in their status.

Table 2 also provides the Univariate analysis of the primary dependent variables in relation to change in substance abuse change. Progression to worse types was associated with factors such as lower than $200 \mathrm{~km}$

\begin{tabular}{|c|c|c|c|c|c|c|}
\hline Variable & Improvement & Without Change & Deterioration & Severe Deterioration & Total & PValue \\
\hline Distance from home & & & & & & 0.001 \\
\hline$<200 \mathrm{~km}$ & $201(6.7)$ & $2441(80.9)$ & $206(6.8)$ & $171(5.7)$ & $3019(100)$ & \\
\hline$>200 \mathrm{~km}$ & $64(6.8)$ & $805(85.5)$ & $38(4)$ & $34(3.6)$ & $941(100)$ & \\
\hline Psychiatric drug use history & & & & & & $<0.0001$ \\
\hline No & $206(6.3)$ & $2779(84.8)$ & $175(5.3)$ & $118(3.6)$ & $3278(100)$ & \\
\hline Yes & $53(10.7)$ & $296(59.9)$ & $63(12.8)$ & $82(16.6)$ & $494(100)$ & \\
\hline Bad relationship with commanders & & & & & & $<0.0001$ \\
\hline Yes & $31(8.1)$ & $220(57.4)$ & $65(17)$ & $67(17.5)$ & $383(100)$ & \\
\hline No & $231(6.8)$ & $2878(84.2)$ & $174(5.1)$ & $135(3.9)$ & $3418(100)$ & \\
\hline Service place dissatisfaction & & & & & & $<0.0001$ \\
\hline Yes & $25(5.6)$ & $300(6)$ & $59(13.2)$ & $64(14.3)$ & $448(100)$ & \\
\hline No & $239(7.1)$ & $2796(83.4)$ & $179(5.3)$ & $140(4.2)$ & $3354(100)$ & \\
\hline Always feeling lonely & & & & & & $<0.0001$ \\
\hline Yes & $38(6.1)$ & $434(69.9)$ & $73(11.8)$ & $76(12.2)$ & $621(100)$ & \\
\hline No & $223(7.1)$ & $2640(83.7)$ & $166(5.3)$ & $124(3.9)$ & $3153(100)$ & \\
\hline Alcohol use in family and with friends & & & & & & $<0.0001$ \\
\hline Yes/Yes & $21(12.1)$ & $81(46.6)$ & $44(25.3)$ & $28(16.1)$ & $174(100)$ & \\
\hline Yes/No & $99(13.6)$ & $464(63.7)$ & $90(12.4)$ & $75(10.3)$ & $728(100)$ & \\
\hline No/No & $135(5)$ & $2371(88.3)$ & $89(3.3)$ & $89(3.3)$ & $2684(100)$ & \\
\hline Suicidal attempt history & & & & & & $<0.0001$ \\
\hline No & $172(6.2)$ & $2362(85.8)$ & $128(4.6)$ & $91(3.3)$ & $2753(100)$ & \\
\hline Yes & $93(7.7)$ & $884(73.2)$ & $116(9.6)$ & $114(9.4)$ & $1207(100)$ & \\
\hline Combat situation & & & & & & 0.015 \\
\hline Normal & $214(6.2)$ & $2836(82.6)$ & $206(6)$ & $178(5.2)$ & $3434(100)$ & \\
\hline Exempted & $28(10.4)$ & $205(75.9)$ & $23(8.5)$ & $14(5.2)$ & $270(100)$ & \\
\hline Living situation & & & & & & $<0.0001$ \\
\hline With family & $243(6.9)$ & $2933(82.7)$ & $214(6)$ & $157(4.4)$ & $3547(100)$ & \\
\hline Alone & $10(7.9)$ & $77(60.6)$ & $8(6.3)$ & $32(25.2)$ & $127(100)$ & \\
\hline Marital status & & & & & & $<0.0001$ \\
\hline Single & $218(6.7)$ & $2694(82.8)$ & $198(6.1)$ & $142(4.4)$ & $3252(100)$ & \\
\hline Married & $39(8.2)$ & $366(77.4)$ & $29(6.1)$ & $39(8.2)$ & $473(100)$ & \\
\hline Divorced-Separated-extramarital contact & $2(3.5)$ & $31(54.4)$ & $7(12.3)$ & $17(29.8)$ & $57(100)$ & \\
\hline Job prior to military service & & & & & & $<0.0001$ \\
\hline Student & $50(4.1)$ & $1054(87.5)$ & $51(4.2)$ & $50(4.1)$ & $1205(100)$ & \\
\hline Unemployed & $14(5.7)$ & $178(72.1)$ & $20(8.1)$ & $35(14.2)$ & $247(100)$ & \\
\hline Employed & $147(8.5)$ & $1390(79.9)$ & $116(6.7)$ & $86(4.9)$ & $1739(100)$ & \\
\hline Education & & & & & & $<0.0001$ \\
\hline Under Diploma & $219(7.8)$ & $2276(80.8)$ & $173(6.1)$ & $148(5.3)$ & $2816(100)$ & \\
\hline Diploma or Higher & $46(4)$ & $970(84.8)$ & $71(6.2)$ & $57(5)$ & $1144(100)$ & \\
\hline Leisure time satisfaction & & & & & & $<0.0001$ \\
\hline Yes & $138(6.5)$ & $1833(86.9)$ & $82(3.9)$ & $57(2.7)$ & $2110(100)$ & \\
\hline Incurious & $62(8.8)$ & $521(73.9)$ & $60(8.5)$ & $62(8.8)$ & $705(100)$ & \\
\hline No & $58(6.1)$ & $720(75.9)$ & $91(9.6)$ & $79(8.3)$ & $948(100)$ & \\
\hline Age of substance abuse onset & & & & & & $<0.0001$ \\
\hline Under 15 & $56(14.2)$ & $203(51.4)$ & $73(18.5)$ & $63(15.9)$ & $395(100)$ & \\
\hline Above 15 & $209(5.9)$ & $3043(85.4)$ & $171(4.8)$ & $142(4)$ & $3565(100)$ & \\
\hline Total changes & $265(6.7)$ & $3246(82)$ & $244(6.1)$ & $205(5.2)$ & $3960(100)$ & \\
\hline
\end{tabular}

${ }^{\mathrm{a}}$ Data are presented as No.(\%). 
distance from home, psychiatric drug use history, bad relationship with commanders, service place dissatisfaction, always feeling lonely, alcohol use in family and with friend, suicidal attempt history, combat situation, living situation, marital status, job prior to military service, educational level, leisure time satisfaction, and age of substance abuse onset.

\subsection{Multivariate Analysis}

All independent variables contributed significantly to the final model, predicting the progression in substance abuse status from "improvement" to "no change", then "deterioration", and finally "severe deterioration" type. The results of backward ordinal regression to determine multivariate predictors are reported in Table 3. Independent factors are divided into 'modifiable' and 'non-modifiable'.

\subsubsection{Modifiable Factors}

The risk of progression to worse type in substance abuse status among soldiers who were lower than $200 \mathrm{~km}$ far

\begin{tabular}{|c|c|c|c|}
\hline Variables & OR, 95\% CI & SE & P Value \\
\hline \multicolumn{4}{|l|}{ Modifiable } \\
\hline \multicolumn{4}{|l|}{ Distance from home, km } \\
\hline$<200$ & $1.54(1.19-1.98)$ & 0.20 & 0.001 \\
\hline$>200$ & Base & - & - \\
\hline \multicolumn{4}{|l|}{ Bad relationship with commanders } \\
\hline Yes & $1.88(1.34-2.62)$ & 0.32 & $<0.0001$ \\
\hline No & Base & - & - \\
\hline \multicolumn{4}{|l|}{ Service place dissatisfaction } \\
\hline Yes & $1.39(1.005-1.92)$ & 0.23 & 0.049 \\
\hline No & Base & - & - \\
\hline \multicolumn{4}{|l|}{ Always feeling lonely } \\
\hline Yes & $1.83(1.37-2.44)$ & 0.27 & $<0.0001$ \\
\hline No & Base & - & - \\
\hline \multicolumn{4}{|l|}{ Combat Situation } \\
\hline Normal & $1.44(0.95-2.16)$ & 0.30 & 0.080 \\
\hline Exempted & Base & - & - \\
\hline \multicolumn{4}{|l|}{ Non-modifiable } \\
\hline \multicolumn{4}{|l|}{ Psychiatric drug use history } \\
\hline No & $0.58(0.42-0.78)$ & 0.09 & 0.001 \\
\hline Yes & Base & - & - \\
\hline \multicolumn{4}{|l|}{ Alcohol use in family and with friend } \\
\hline Yes/Yes & $2.76(1.76-4.31)$ & 0.63 & $<0.0001$ \\
\hline Yes/No & $1.23(0.93-1.61)$ & 0.17 & 0.13 \\
\hline No/No & Base & - & - \\
\hline \multicolumn{4}{|l|}{ Suicidal attempt history } \\
\hline No & $0.76(0.60-0.95)$ & 0.09 & 0.32 \\
\hline Yes & Base & - & - \\
\hline \multicolumn{4}{|l|}{ Living situation } \\
\hline With family & $0.41(0.24-0.69)$ & 0.11 & 0.001 \\
\hline Alone & Base & - & - \\
\hline \multicolumn{4}{|l|}{ Marital status } \\
\hline Single & $0.26(0.12-0.55)$ & 0.10 & 0.001 \\
\hline Married & $0.29(0.12-0.65)$ & 0.12 & 0.004 \\
\hline Divorce/Separated/Extramarital contact & Base & - & - \\
\hline \multicolumn{4}{|l|}{ Job prior to military course } \\
\hline Student & $1.09(0.87-1.35)$ & 0.12 & 0.436 \\
\hline Unemployed & $1.61(1.09-2.37)$ & 0.32 & 0.019 \\
\hline Employed & Base & - & - \\
\hline \multicolumn{4}{|l|}{ Leisure time satisfaction } \\
\hline Yes & $0.68(0.52-0.88)$ & 0.09 & 0.004 \\
\hline Incurious & $0.83(0.61-1.12)$ & 0.13 & 0.259 \\
\hline No & Base & - & - \\
\hline \multicolumn{4}{|l|}{ Age of substance abuse onset } \\
\hline Under 15 & $1.71(1.22-2.38)$ & 0.29 & 0.001 \\
\hline Above 15 & Base & - & - \\
\hline
\end{tabular}


from home was 1.54 times greater than those who served more than $200 \mathrm{~km}(\mathrm{P}=0.001)$ away from home. Also soldiers who had bad relationship with commanders had 1.88 times more chance of progression to worse type $(\mathrm{P}=$ $0.000)$ compared to others. Service place dissatisfaction made soldiers have higher risk of progression to worse type $(\mathrm{OR}=1.39, \mathrm{P}=0.049)$. Finally, soldiers who always felt lonely had 1.83 times greater odds of getting in the worse type $(P=0.000)$. So if all these factors were cumulated, soldier have $7.3(1.54 \times 1.44 \times 1.88 \times 1.83)$ times greater odds of being in worse category compared to the base groups.

\subsubsection{Non-modifiable Factors}

Soldiers who had psychiatric drug use history have higher risk of getting in the worse type $(\mathrm{OR}=1.72, \mathrm{P}=$ 0.001). Soldiers whose both family and friends have used alcohol had 2.76 times higher odds of getting in the worse type compared to the base group $(\mathrm{P}<0.0001)$. But those soldiers whose family or friends have used alcohol had no significant risk difference with the base group. Suicidal attempt history made soldiers have higher risk of getting in the worse type $(\mathrm{OR}=1.31, \mathrm{P}=0.023)$. Living without family increased the chance of being in the worse category compared to the base group $(\mathrm{OR}=2.43$, $\mathrm{P}=0.001)$. Soldiers who have experienced divorce, separation, and extramarital contact have 3.84 and 3.44 times higher odds of getting in worse type compare to singles $(\mathrm{P}=0.001)$ and married people $(0.004)$, respectively. Unemployment made soldiers have higher risk of getting in worse type compared to employed ones $(\mathrm{OR}=1.61, \mathrm{P}$ $=0.019$ ), but there was not any significant difference between employed and student people. Soldiers who had leisure time dissatisfaction had 1.47 times greater odds of getting in worse type compared to satisfied people ( $\mathrm{P}=$ 0.004 ), but the risk of incurious and unsatisfied people were the same. Finally, soldiers who had started substance abuse prior to age 15 had 1.71 times higher odds of getting in worse type $(\mathrm{P}=0.001)$.

\section{Discussion}

The aim of this study was to determine the predictors of change in substance abuse status of soldiers during military service. In our study, it is demonstrated that alcohol use in family and with friends, living alone, psychiatric drug use history, suicidal attempt history, marital status, job prior to military service, leisure time dissatisfaction and age of substance abuse onset are non-modifiable factors of increasing the chance of progression in substance abuse status from "improvement" to "no change", "deterioration", and "severe deterioration". Also distance from home, bad relationship with commanders, service place dissatisfaction and always feeling lonely are the modifiable risk factors of increasing 7.3 times the chance of mentioned progression.

There is some evidence that having a parent who abused substances play a crucial role in the etiology of il- legal substance use initiation and continuation (26-30). Also, Hofler et al. in their study on 1228 teenager respondents showed that family history of substance use disorders and peer group drug use predict the progression to cannabis use from "no use", to "one time only", then "repeated use", and finally "regular use" (31). Many studies demonstrated that parental and peer drinking predicted heavy drinking (32-34). Hayatbakhsh et al. showed in two studies that maternal smoking and alcohol consumption were strongly associated with young adult cannabis use, early onset of smoking, and use disorder $(28,35)$. Our study confirmed these findings.

Some studies have demonstrated that male gender is an important etiology of illegal substance use initiation and continuation $(27,28,30)$. Ferrier-Auerbach et al. hypothesize that higher alcohol use in the military will be associated with demographic variables, including younger age, male gender, lower levels of education, and unmarried status (36). This finding confirmed by AnsariMoghadam et al. who indicated that male gender, single life, low level of education act as facilitators for transition to use new drugs (37). However, Maggs et al. showed that greater academic performance predicted heavy drinking (34). Heinz et al. demonstrated that social support has been indicated in improved substance-use outcomes and the quality of social support in marital relationship (i.e. functional social support) has been associated with substance-use outcomes in important and meaningful ways (29). We did not assess the gender variable in our study, but we showed that marital status and job prior to military service are the important demographic predictors for deterioration in substance abuse status. Lower level of education in univariate analysis was associated by being in improvement type, but it was not known as predictor in multivariate analysis.

Studies have shown that parent's educational degree and lower levels of parental verbal reasoning are associated with illegal substance use initiation and continuation (27-30). Also single-parent household and less harmonious family relationships predicted heavy drinking $(33,34,38)$ and changes in maternal marital status were strong early life predictors of young adult cannabis use and disorder (28). In our study, living alone was a predictor for getting worse in substance abuse situation, which can be due to instability of family or individual reasons.

Brady and Sinha showed in their study that patients with anxiety or mood disorders are more prone to use substances for alleviating distressing symptoms (38). There is some evidence that early onset of drug use, more thought problems, weak social problem solving skills, and use of legal substances at baseline play a pivotal role in the etiology of illegal substance use initiation and continuation $(27,30,39)$. Also one study indicated that early onset of substance use and type of first used drug act as facilitators for transition to new drugs (37). Kaplow et al. showed that overactivity is a predictor of early-onset substance use (30). Hofler et al. in their study on 1228 
teenager respondents showed that self-esteem and competence, unconditional commitment to not using drugs, immediate availability of drugs, and previous history of nicotine dependence and alcohol use disorders predict the progression to cannabis use from "no use", to "one time only", then "repeated use", and finally "regular use" (31). Risk taking, use of cigarettes and marijuana, higher social maladjustment, greater academic performance, less internalizing problems, more truancy, and earlier school-leaving plans predicted heavy drinking (32-34, 38). Ferrier-Auerbach et al. also hypothesize that higher alcohol use in the military will be associated with personality disorders, including higher levels of negative emotionality and disconstraint; as well as pre-deployment mental health problems such as higher levels of PTSD and depression (36). Early life course predictors of cannabis use were studied. In this regard, school performance, childhood sexual abuse, early adolescence smoking and alcohol consumption, as well as adolescent aggression/ delinquency were strongly associated with young adult cannabis use and substance use disorder (28). One study identified patients with substance use disorders who deteriorated during treatment, and examined baseline predictors of deterioration. Deterioration was predicted by not having close friends. Patients who had both alcohol and drug dependency, personality disorder diagnosis, and those who had a shorter episode of care and fewer outpatient-mental-health visits, were more likely to deteriorate (40). Child externalizing (at age 5) significantly predicted the early onset of smoking (35).

Our study demonstrated that psychiatric drug use history, self-mutilation or suicide history, leisure time dissatisfaction, bad relationship with commanders, service place dissatisfaction, and feeling always lonely are factors of increasing in the chance of progression in substance abuse status from "improvement" to "no change", "deterioration" and finally "severe deterioration". We also showed that distance from home (less than $200 \mathrm{~km}$ ) is a predictor of getting worse, which can be due to maintaining access to substances. Age of substance abuse onset was associated significantly to getting in worse type, which confirms other studies. In our study, exemption from combat was significantly associated with improving in substance abuse status but in multivariate analysis it was not a predictor.

One of the study limitations was the information bias due to incorrect responses of some participants. To ease this problem, participants were assured of the privacy of information. The other limitation was lack of specific assessment in each stratum due to executive problems, which lead to non-specific generalizability. Substance abuse information was collected only subjectively with its own limitation of validity. Also in this study, dependent variables were defined totally for all substances, which may lower the specificity of results for each group of substance abusers. The strength of this study was its target sample from a wide area of the country and its im- portant setting, the military service. The other strength of this study is defining subtypes of 'change' in substance abuse situation.

Alcohol use in family and with friends, living without family, psychiatric drug use history, suicidal attempt history, divorce, separation, extramarital contact, unemployment, leisure time dissatisfaction, distance from home less than $200 \mathrm{~km}$, bad relationship with commanders, service place dissatisfaction, always feeling lonely, and age of substance abuse onset all contributed significantly to the final model, predicting the progression to the substance abuse status from 'improvement' to 'no change', then 'deterioration' and finally ‘severe deterioration'. Considering non-modifiable risk factors, commanders may recognize more vulnerable soldiers and try to resolve modifiable ones and decrease the risk of getting worse as much as 7.3 times.

\section{Acknowledgements}

This research was supported by a grant from Baqiyatallah university of medical sciences, Tehran, Iran. We gratefully acknowledge them and all persons who helped us in this research.

\section{Authors' Contributions}

Alireza Karambakhsh, Mahmood Salesi, and Mostafa Heydari contributed to the analysis and interpretation of data, statistical, and cost-effectiveness analysis as well as critical revision of the manuscript. Alireza Mehrazmay contributed to the provision, collection, and assemblage of study data as well as writing the manuscript. Khodabakhsh Ahmadi contributed to critical revision and final approval of the study.

\section{Funding/Support}

This study was supported by a grant from Baqiyatallah university of medical sciences and a teaching and research scholarship from behavioral sciences research center (Dr. Khodabakhsh Ahmadi).

\section{References}

1. UNODC. World drug report: 2013. Vienna: United Nations Office on Drugs and Crime; 2013.

2. Razzaghi EM, Movaghar AR, Green TC, Khoshnood K. Profiles of risk: a qualitative study of injecting drug users in Tehran, Iran. Harm Reduct J. 2006;3:12.

3. Moosazadeh M, Ziaaddini H, Mirzazadeh A, Ashrafi-Asgarabad A Haghdoost AA. Meta-analysis of Smoking Prevalence in Iran. Addict Health. 2013;5(3-4):140-53.

4. WHO. Global status report on alcohol and health 2011. Genebra: WHO; 2011.

5. Statistical Center of Iran. Selected Findings of the 2011 National Population and. Iran. 2011. page 27. Available from: http://www. amar.org.ir/Portals/1/Iran/90.pdf/

6. Kao TC, Schneider SJ, Hoffman KJ. Co-occurrence of alcohol, smokeless tobacco, cigarette, and illicit drug use by lower ranking military personnel. Addict Behav. 2000;25(2):253-62.

7. Azad-Marzabadi E, Salimi S. Study on job stress in a military unit 
MilMed J. 2005;6(4):279-84.

8. Ahmadi K, Alireza K. Stress and Job Satisfaction among Air Force Military Pilots.J of Social Sci. 2007;3(3):159-63.

9. Tomkins SS. Psychological model for smoking behavior. Am JPublic Health Nations Health. 1966;56(12):Suppl 56:17-20.

10. Leventhal H, Cleary PD. The smoking problem: a review of the research and theory in behavioral risk modification. Psychol Bull. 1980;88(2):370-405.

11. Russell JA, Mehrabian A. The mediating role of emotions in alcohol use. J Stud Alcohol.1975;36(11):1508-36.

12. Shiffman S. Relapse following smoking cessation: a situational analysis. J Consult Clin Psychol. 1982;50(1):71-86.

13. Marlatt GA, Donovan D. Relapse prevention: Maintenance strategies in the treatment of addictive behaviors. New York: Guilford Press; 2005.

14. Shiffman S. Coping and substance use. United States: Academic Press; 1985.

15. Koob GF, Le Moal M. Drug abuse: hedonic homeostatic dysregulation. Science. 1997;278(5335):52-8.

16. Sinha R. Chronic stress, drug use, and vulnerability to addiction. Ann NYAcad Sci. 2008;1141:105-30.

17. Lazarus RS. Psychological stress and the coping process. McGrawHill: New York,; 1966.

18. Lazarus RS, Folkman. S. Stress, Appraisal, and Coping. New York: Springer; 1986.

19. Carver CS, Scheier MF, Weintraub JK. Assessing coping strategies: a theoretically based approach.J Pers Soc Psychol.1989;56(2):267-83.

20. Izadi M, Sajjadi A, Ghafourian AR. Effect of education on the knowledge of soldiers about smoking hazards. J Mil Med. 2009;11(2):81-7.

21. Ames G, Cunradi C. Alcohol use and preventing alcohol-related problems among young adults in the military. Alcohol Res Health. 2004;28(4):252-7.

22. Marsden ME, Bray RM, Herbold JR. Substance use and health among U.S. military personnel: findings from the 1985 Worldwide Survey. Prev Med.1988;17(3):366-76.

23. Jedrzejczak M, Blaszczyk J. Attitudes of soldiers taking drugs to military service, training, and discipline. Mil Med. 2005;170(8):691-5.

24. Knight K, Simpson DD, Morey JT. An evaluation of the TCU Drug Screen. Washington, DC: National Institute of Justice, Office of Justice Programs, US Department of Justice; 2002.

25. Makela K. Studies of the reliability and validity of the Addiction Severity Index. Addiction. 2004;99(4):398-410.

26. Cox RJ, Blow AJ, Maier KS, Parra Cardona JR. Covariates of substance-use initiation for Venezuelan youth: using a multilevel approach to guide prevention programs. J Stud Alcohol Drugs. 2010;71(3):424-33.

27. Bojorquez I, Fernandez-Varela H, Gorab A, Solis C. Factors associ- ated with illegal substance use initiation among young students in Mexico City. Drug Alcohol Rev. 2010;29(3):286-92.

28. Hayatbakhsh MR, Najman JM, Bor W, O'Callaghan MJ, Williams GM. Multiple risk factor model predicting cannabis use and use disorders: a longitudinal study. Am J Drug Alcohol Abuse. 2009;35(6):399-407.

29. Heinz AJ, Wu J, Witkiewitz K, Epstein DH, Preston KL. Marriage and relationship closeness as predictors of cocaine and heroin use. Addict Behav. 2009;34(3):258-63.

30. Kaplow JB, Curran PJ, Dodge KA, Conduct Problems Prevention Research G. Child, parent, and peer predictors of early-onset substance use: a multisite longitudinal study. J Abnorm Child Psychol. 2002;30(3):199-216.

31. Hofler M, Lieb R, Perkonigg A, Schuster P, Sonntag H, Wittchen HU. Covariates of cannabis use progression in a representative population sample of adolescents: a prospective examination of vulnerability and risk factors. Addiction. 1999;94(11):1679-94.

32. Merline A, Jager J, Schulenberg JE. Adolescent risk factors for adult alcohol use and abuse: stability and change of predictive value across early and middle adulthood. Addiction. 2008;103 Suppl 1:84-99.

33. Yeh MY, Chiang IC. Comparison of the predictors of alcohol use and misuse among Han and aboriginal students in Taiwan. Addict Behav. 2005;30(5):989-1000.

34. Maggs JL, Patrick ME, Feinstein L. Childhood and adolescent predictors of alcohol use and problems in adolescence and adulthood in the National Child Development Study. Addiction. 2008;103 Suppl 1:7-22.

35. Hayatbakhsh R, Mamun AA, Williams GM, O'Callaghan MJ, Najman JM. Early childhood predictors of early onset of smoking: a birth prospective study. Addict Behav. 2013;38(10):2513-9.

36. Ferrier-Auerbach AG, Kehle SM, Erbes CR, Arbisi PA, Thuras P, Polusny MA. Predictors of alcohol use prior to deployment in National Guard Soldiers. Addict Behav. 2009;34(8):625-31.

37. Ansari-Moghaddam A, Habybabady RH, Shakiba M, Mirzaei R, Shahriyari F, Aghaei S. Predictors of initiation, continuation and transition of drug use in south-eastern Iran.J Pak Med Assoc. 2012;62(7):698-703.

38. Englund MM, Egeland B, Oliva EM, Collins WA. Childhood and adolescent predictors of heavy drinking and alcohol use disorders in early adulthood: a longitudinal developmental analysis. Addiction. 2008;103 Suppl 1:23-35.

39. Kokkevi A, Nic Gabhainn S, Spyropoulou M, Risk Behaviour Focus Group of the H. Early initiation of cannabis use: a cross-national European perspective. J Adolesc Health. 2006;39(5):712-9.

40. Moos RH, Moos BS, Finney JW. Predictors of deterioration among patients with substance-use disorders. J Clin Psychol. 2001;57(12):1403-19. 